\title{
Effect of High-Intensity Interval Training on Aerobic Capacity and Heart Rate Control of Heart Transplant Recipients: a Systematic Review with Meta-Analysis
}

Lino Sergio Rocha Conceição ${ }^{1,2,3}$, PhD; Caroline Oliveira Gois ${ }^{1,2,3}$, PT; Raiane Eunice Santos Fernandes ${ }^{1,2,3}$; Paulo Ricardo Saquete Martins-Filho ${ }^{4}$, PhD; Mansueto Gomes Neto ${ }^{5}, \mathrm{PhD}$; Victor Ribeiro Neves ${ }^{6}$, PhD; Vitor Oliveira Carvalho ${ }^{1,2,3}, \mathrm{PhD}$

\begin{abstract}
Introduction: Heart transplantation (HTx) is the gold standard procedure for selected individuals with refractory heart failure. Highintensity interval training (HIIT) is safe and allows patients to exercise in high intensity for longer time when compared to moderateintensity continuous training (MICT). The primary aim of this study was to perform a systematic review and meta-analysis about the effect of HIIT compared to MICT on exercise capacity, peak heart rate, and heart rate reserve in HTx recipients. Secondarily, we pooled data comparing MICT and no exercise training in these patients.

Methods: This systematic review followed the standardization of the Preferred Reporting Items for Systematic Reviews and Metaanalyses statement and the Cochrane Collaboration Handbook. We presented the treatment effects of HIIT on the outcomes of interest as mean difference (MD) and $95 \%$ confidence interval (Cl). Meta-
\end{abstract}

analysis was performed using the random-effects, generic inverse variance method.

Results: HIIT improved peak oxygen consumption (peakVO2) (MD = 2.1; 95\% Cl 1.1, 3.1; $P<0.0001)$, peak heart rate $(\mathrm{MD}=3.4 ; 95 \%$ $\mathrm{Cl} 0.8,5.9 ; P=0.009)$, and heart rate reserve $(\mathrm{MD}=4.8 ; 95 \% \mathrm{Cl}-0.05$, 9.6; $P=0.05$ ) compared to MICT. Improvements on peakVO ${ }_{2}(\mathrm{MD}=3.5$; $95 \% \mathrm{Cl} 2.3,4.7 ; P<0.00001)$ and peak heart rate $(\mathrm{MD}=5.6 ; 95 \% \mathrm{Cl} 1.6$, 9.6; $P=0.006$ ) were found comparing HIIT and no exercise training.

Conclusion: Current available evidence suggests that HIIT leads to improvements on peakVO $\mathrm{O}_{2}$, peak heart rate, and heart rate reserve compared to MICT in HTx recipients. However, the superiority of HIIT should be tested in isocaloric protocols.

Keywords: Heart Transplantation. High-Intensity Interval Training. Exercise Tolerance. Heart Failure.

\section{Abbreviations, acronyms \& symbols}

\begin{tabular}{llll}
\hline ACT & Active recovery & MD & $=$ Mean difference \\
AIT & $=$ Aerobic interval training & MICT & $=$ Moderate-intensity continuous training \\
$\mathrm{CI}$ & $=$ Confidence interval & NR & $=$ Not reported \\
$\mathrm{F}$ & $=$ Female & PeakVO $_{2}$ & $=$ Peak oxygen consumption \\
HIIT & $=$ High-intensity interval training & RCTs & $=$ Randomized controlled trials \\
HR & $=$ Hear rate & SD & $=$ Standard deviation \\
HRQoL & $=$ Health-related quality of life & SDc & $=$ Standard deviation of change \\
HTx & $=$ Heart transplantation & SE & $=$ Standard error \\
M & $=$ Male & & \\
\end{tabular}

'Department of Physical Therapy, Universidade Federal de Sergipe (UFS), São Cristóvão, Sergipe, Brazil.

2Post-Graduation Program in Health Sciences, Universidade Federal de Sergipe (UFS), São Cristóvão, Sergipe, Brazil.

${ }^{3}$ The GREAT Group (GRupo de Estudos em ATividade física), Universidade Federal de Sergipe (UFS), São Cristóvão, Sergipe, Brazil.

${ }^{4}$ Investigative Pathology Laboratory, Universidade Federal de Sergipe (UFS), São Cristóvão, Sergipe, Brazil.

${ }^{5}$ Department of Physical Therapy, Universidade Federal da Bahia (UFBa), Salvador, Bahia, Brazil.

6Universidade de Pernambuco (UPE), Pernambuco, Recife, Brazil.
This study was carried out at the Department of Physical Therapy, Universidade Federal de Sergipe (UFS), São Cristóvão, Sergipe, Brazil.

Correspondence Address:

Lino Sergio Rocha Conceição

(iD) https://orcid.org/0000-0002-9738-7613

Universidade Federal de Sergipe

Rua Cláudio Batista, s/n, Bairro Sanatório, Aracaju, Sergipe, SE, Brazil

Zip Code: 49060-100

E-mail: linosergiorocha@gmail.com 


\section{INTRODUCTION}

Heart transplantation $(\mathrm{HTx})$ is the gold standard procedure for selected individuals with end-stage heart failure ${ }^{[1]}$. Even knowing that HTx improves patients' exercise tolerance, it is not restored to normal values ${ }^{[2]}$. The concern about exercise tolerance in $\mathrm{HTx}$ recipients is based on the association between peak oxygen consumption (peakVO${ }_{2}$ ), the gold standard method to assess cardiorespiratory fitness, and survival| ${ }^{[3,4]}$.

Several studies have demonstrated the positive effects of aerobic exercise training on peakVO $\mathrm{H}_{2}$ in $\mathrm{HTx}$ recipients ${ }^{[5-7]}$. However, there is no consensus on how, when, or at what intensity exercise should be performed by HTx patients ${ }^{[8]}$. High-intensity interval training (HIIT) allows patients to exercise in higher intensity when compared to standard continuous training. A previous well performed meta-analysis ${ }^{[9]}$ showed that HIIT was safe and effective in improving peakVO in HTx recipients when compared to no training. However, the lack of studies that compared HIIT with moderate-intensity continuous training (MICT) limited the previous meta-analysis. Moreover, conflicting results about HIIT superiority are still under discussion in cardiovascular rehabilitation ${ }^{[10,11]}$.

Since the previous meta-analysis was published ${ }^{[9]}$, new randomized controlled trials (RCTs) comparing HIIT with MICT were published ${ }^{[12,13]}$. Due to the new available data, the primary aim of the present study was to perform a systematic review and meta-analysis to synthesize evidence about the effect of HIIT compared to MICT on exercise capacity, peak heart rate, and heart rate reserve in HTx recipients. Secondarily, we pool data from trials comparing HIIT and no exercise training in these patients.

\section{METHODS}

This study was conducted following the Preferred Reporting Items for Systematic Reviews and Meta-analyses statement ${ }^{[14]}$ and supplemented by guidance from the Cochrane Collaboration Handbook for Systematic Reviews of Interventions ${ }^{[15]}$. A flow diagram showing the reference screening and study selection is presented on Figure 1.

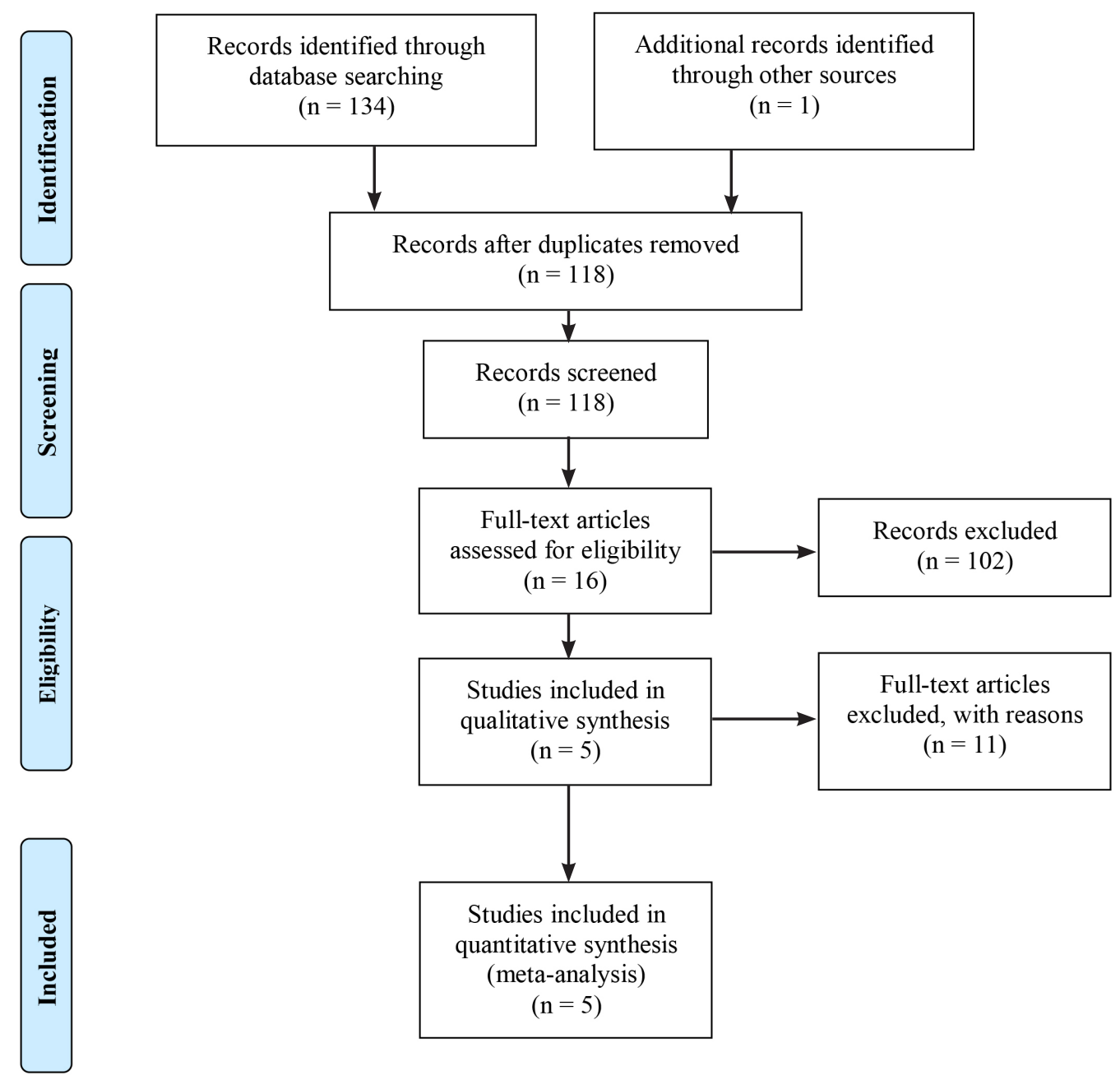

Fig. 1 - Flow diagram showing the reference screening and study selection 


\section{Eligibility Criteria}

To establish the eligibility criteria we used the following PICOT elements (standing for Participants, Intervention, Comparison, Outcomes, and Study type): Population, HTx recipients; Intervention, HIIT; Comparison, MICT or no exercise training; Primary outcome, peakVO $2(\mathrm{ml} / \mathrm{kg} / \mathrm{min})$; Secondary outcomes, peak heart rate and heart rate reserve (bpm); Study type, RCTs.

\section{Data Collection and Analysis}

Two independent reviewers (COG and RESF) searched for relevant studies according to title and abstract. If at least one of the reviewers considered one reference eligible, the full text was obtained for a complete assessment. Then, the two reviewers assessed the full text according to the eligibility criteria. Thereafter, the following information from the studies were extracted:

\section{Search Strategy}

We searched for references in PubMed, Scopus, and Cochrane Central Register of Controlled Trials up to February 2019. A gray literature search included Google Scholar and OpenThesis. The first 100 results of the Google Scholar search were analyzed. The search was limited to studies published in full-text versions, without language restriction. Search strategy is provided in the online supplement. The reference lists of all eligible studies and reviews were also scanned to identify additional studies for inclusion. The authors were contact by e-mail for confirmation of any data or additional information if needed.

\section{Quality of the Studies}

Risk of bias was assessed according to the Cochrane guidelines for RCTs. Seven domains were assessed for evaluation: sequence generation and allocation concealment (selection bias), blinding of participants and personnel (performance bias), blinding of outcome assessment (detection bias), incomplete outcome data (attrition bias), selective outcome reporting (reporting bias), and other potential sources of bias (Figure 2). Risk of bias was rated as low, unclear, or high according to established criteria (Figure 3) ${ }^{[16]}$.

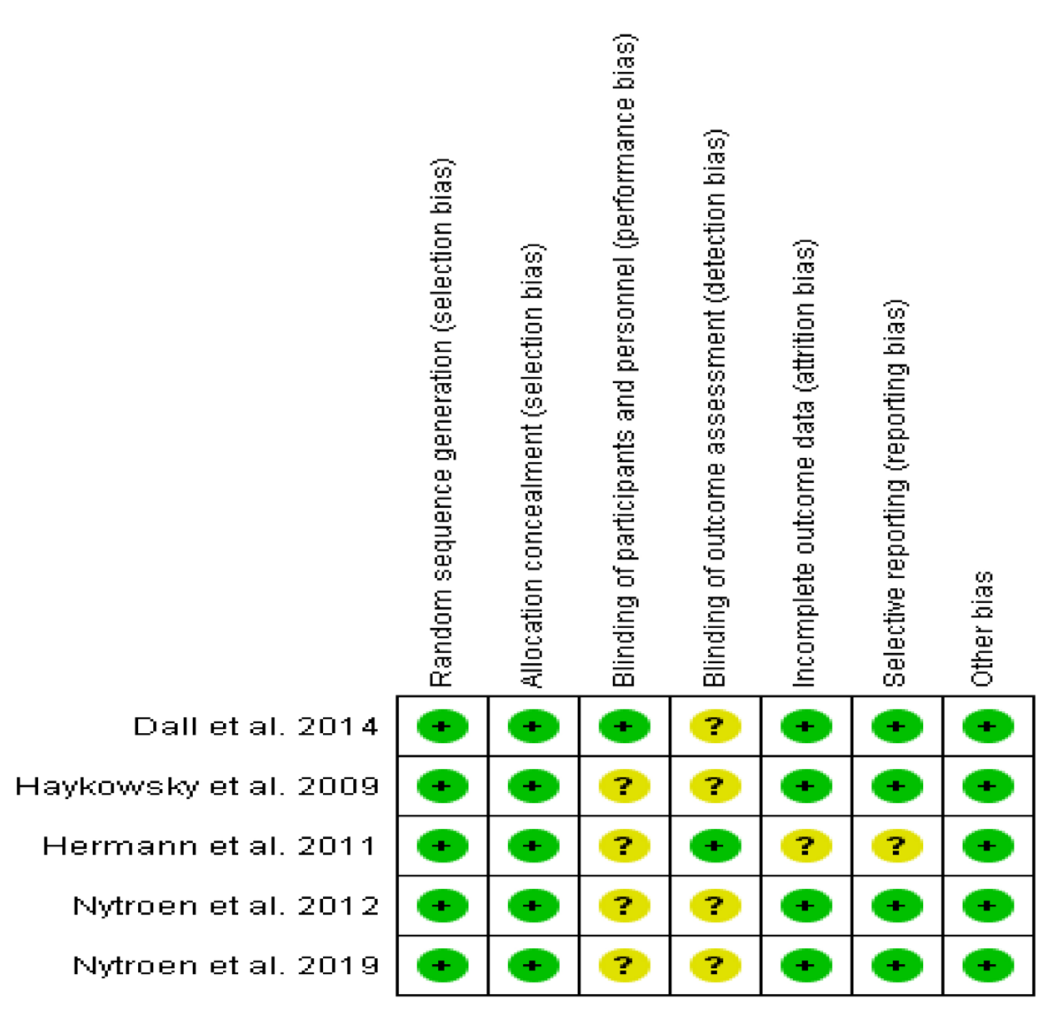

Fig. 2 - Risk of bias summary: review authors' assessments about each risk of bias item for each included study.

Random sequence generation (selection bias)

Allocation concealment (selection bias)

Blinding of participants and personnel (performance bias)

Blinding of outcome assessment (detection bias)

Incomplete outcome data (attrition bias)

Selective reporting (reporting bias)
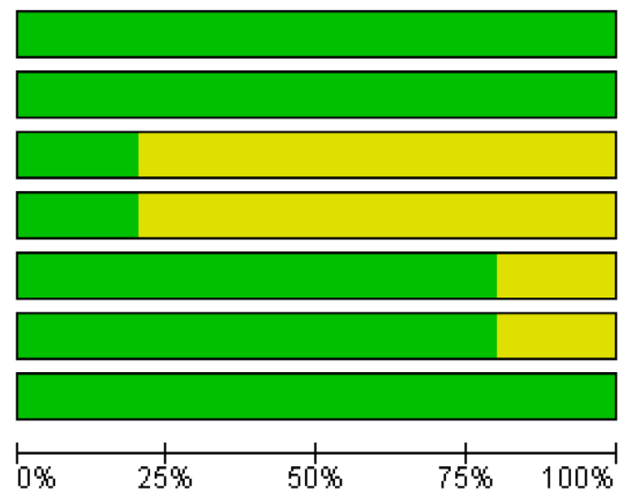

Other bias

Low risk of bias

Unclear risk of bias

High risk of bias

Fig. 3 - Risk of bias graph: review authors' assessments about each risk of bias item presented as percentages across all included studies 
demographic characteristics of study participants, exercise protocols, adverse events, and outcome data. Values (mean difference [MD] and standard deviation [SD]) for peakVO, peak heart rate, and heart rate reserve were extracted before and after intervention.

The meta-analysis was performed using the change between pre- and post-intervention means for each intervention group and the change SD calculated. If the SD of change [SDC]) for a given outcome was not reported, the formula:

$$
\mathrm{SDC}=\sqrt{ }\left[\left(\mathrm{SD}_{\text {pre }}\right)^{2}+\left(\mathrm{SD}_{\text {post }}\right)^{2}-\left(2 \times \text { corr }_{\text {pre,post }} \times \mathrm{SD}_{\text {pre }} \times \mathrm{SD}_{\text {post }}\right)\right]
$$

was applied. SD pre, SD post, and corr prepost represent the SD of the pre-intervention value, the SD of the post-intervention value, and the correlation coefficient between pre- and post-intervention values, respectively. The corr pre,post was conservatively set at 0.5 . Mean changes were pooled using the random-effects, generic inverse variance method. A forest plot was used to graphically present the effect sizes and the 95\% confidence intervals (Cls). A two-tailed $P$-value of $<0.05$ was used to determine significance. Statistical heterogeneity was assessed by using the Cochran $Q$ test ${ }^{[17]}$ and quantified by the $\mathrm{I}^{2}$ index ${ }^{[18]}$.

Table 1. Characteristics of included studies.

\begin{tabular}{|c|c|c|c|c|c|c|c|c|c|}
\hline Study & Disease & $\begin{array}{c}\text { Sample size } \\
\text { (including } \\
\text { dropouts) }\end{array}$ & Gender & $\begin{array}{c}\text { Age } \\
\text { (years) }\end{array}$ & $\begin{array}{c}\text { Time after } \\
\text { transplantation }\end{array}$ & Outcomes & Key findings & $\begin{array}{l}\text { Dropouts } \\
\text { (\%) }\end{array}$ & $\begin{array}{l}\text { Dropouts } \\
\text { before } \\
\text { and after } \\
\text { intervention }\end{array}$ \\
\hline $\begin{array}{l}\text { Nytrøen et } \\
\text { al. }{ }^{[8]}, 2019\end{array}$ & HTx & 81 & $\begin{array}{l}M(66) / \\
F(15)\end{array}$ & 50 & 3 months & $\begin{array}{l}\text { PeakVO } \\
\text { HRQoL, left } \\
\text { ventricular } \\
\text { function, } \\
\text { endothelial } \\
\text { function, and } \\
\text { biomarkers }\end{array}$ & $\begin{array}{c}\text { HIIT group } \\
\text { demonstrated } \\
\text { greater } \\
\text { improvements } \\
\text { than those } \\
\text { observed in the } \\
\text { MICT group } \\
\text { (mean difference: } \\
1.8 \mathrm{ml} / \mathrm{kg} / \mathrm{min} \text { ) }\end{array}$ & $3.8 \%$ & $3.8 \%$ \\
\hline $\begin{array}{c}\text { Dall et al. }{ }^{[13]}, \\
2014\end{array}$ & $\begin{array}{l}\text { HTx (normal } \\
\text { chronotropic } \\
\text { response and } \\
\text { chronotropic } \\
\text { impairment) }\end{array}$ & $20(16)$ & $\begin{array}{l}M(12) / \\
F(4)\end{array}$ & 51.9 & 6.4 years & $\begin{array}{c}\text { PeakVO }{ }_{2,} \\
\text { blood pressure, } \\
\text { HRpeak, HRrest, } \\
\text { HRreserve, } \\
\text { HRrecovery, } \\
\text { workload }\end{array}$ & $\begin{array}{c}\text { There was an } \\
\text { improve in } \\
\text { peakVO } \mathrm{O}_{2}(0,001) \text {, } \\
\text { HRpeak }(0,014) \text {, } \\
\text { and HRreserve } \\
(0,012)\end{array}$ & All - $3(20 \%)$ & $\begin{array}{l}\text { It was a } \\
\text { crossover } \\
\text { study. NR }\end{array}$ \\
\hline $\begin{array}{l}\text { Nytrøen et } \\
\text { al. }{ }^{[18]}, 2012\end{array}$ & HTx & $57(52)$ & $\begin{array}{l}M(33) / \\
F(15)\end{array}$ & 51 & 4.1 years & $\begin{array}{c}\text { Exercise } \\
\text { capacity } \\
\text { (peakVO } \\
\text { and peakVO } \\
\text { predicted), } \\
\text { body } \\
\text { composition, } \\
\text { biochemistry, } \\
\text { and HRQoL }\end{array}$ & $\begin{array}{c}\text { HIIT improved } \\
\text { peakVO } 2(0.001), \\
\text { HRreserve } \\
(0,002), \text { HRpeak } \\
(0.035)\end{array}$ & All - 9 (15\%) & $\begin{array}{c}\text { HIlt - } 2(8 \%), \\
\text { control group } \\
-2(8 \%)\end{array}$ \\
\hline $\begin{array}{l}\text { Hermann et } \\
\text { al. }{ }^{[19]}, 2011\end{array}$ & $H T x$ & $30(27)$ & $\begin{array}{l}M(22) / \\
F(5)\end{array}$ & 50 & 6,9 years & $\begin{array}{c}\text { PeakVO} \\
\text { endothelial } \\
\text { function, } \\
\text { blood pressure, } \\
\text { markers of } \\
\text { inflammation }\end{array}$ & $\begin{array}{c}\text { PeakVO } \mathrm{O}_{2} \text { was } \\
\text { higher in the HIIT } \\
\text { group }(0,001) \text {, } \\
\text { flow-mediated } \\
\text { vasodilation } \\
(0,048) \text {, reduced } \\
\text { blood systolic } \\
\text { pressure }(0,03), \\
\text { reduced plasma } \\
\text { levels }(0,02)\end{array}$ & All - 3 (10\%) & $\begin{array}{c}\text { HIIT - } 2(6,7 \%), \\
\text { control group } \\
-1(3,3 \%)\end{array}$ \\
\hline $\begin{array}{c}\text { Haykowsky } \\
\text { et al. }{ }^{[5]} \\
2009\end{array}$ & HTx & 43 & $\begin{array}{l}M(22) / \\
F(21)\end{array}$ & 57 & 4.9 years & $\begin{array}{c}\text { Exercise } \\
\text { capacity } \\
\left(\text { peakVO } \mathrm{N}_{2}\right) \text {, left } \\
\text { ventricular } \\
\text { systolic function } \\
\text { and peripheral } \\
\text { vascular } \\
\text { function }\end{array}$ & $\begin{array}{c}\text { PeakVO }{ }_{2} \text { change } \\
\text { for HIIT of } 3.11 \\
\mathrm{ml} / \mathrm{kg} / \mathrm{min}\end{array}$ & All - $9(15 \%)$ & $\begin{array}{c}\text { HIlt - } 2(8 \%), \\
\text { control group } \\
-2(8 \%)\end{array}$ \\
\hline
\end{tabular}

$\mathrm{F}=$ female; $\mathrm{HIIT}=$ high-intensity interval training; $\mathrm{HR}=$ heart rate; $\mathrm{HRQOL}=$ health-related quality of life; $\mathrm{HTX}=$ heart transplantation; $\mathrm{M=male;} \mathrm{MICT}=$ moderateintensity continuous training; $\mathrm{NR}=$ not reported; peakVO$_{2}=$ peak oxygen consumption 
We conducted all analyses using Review Manager 5.3 (Cochrane IMS, Copenhagen, Denmark).

\section{RESULTS}

\section{Studies Characteristics}

Five $\mathrm{RCTS} \mathrm{s}^{[5,12,13]}$ (total of $212 \mathrm{HTx}$ recipients with mean age of 57 years) were included in this systematic review. Exercise protocols were well reported (Tables 1 and 2). Follow-up periods were also well reported among studies: eight weeks ${ }^{[17,18]}, 12$ weeks $^{[19,20]}$, and one year ${ }^{[8]}$. No serious adverse events were reported by the studies. In general, the studies presented a low/uncertain risk of bias. Figure 3 presents results of individual assessment by Cochrane risk of bias.

\section{Overall Analysis}

HIIT improved peakVO $2(\mathrm{MD}=2.1 ; 95 \% \mathrm{Cl} 1.1,3.1 ; P<0.0001)$ (Figure $4 \mathrm{~A})$, peak heart rate $(\mathrm{MD}=3.4 ; 95 \% \mathrm{Cl} 0.8,5.9 ; P=0.009)$

Table 2. Characteristics of the HIIT vs. MICT intervention in the trials included in the review.

\begin{tabular}{|c|c|c|c|c|c|c|c|c|}
\hline Study & $\begin{array}{l}\text { Type of } \\
\text { exercise }\end{array}$ & $\begin{array}{c}\mathrm{VO}_{2} \\
\text { measurement }\end{array}$ & Intensity & $\begin{array}{l}\text { Trained } \\
\text { intensity }\end{array}$ & Volume & $\begin{array}{l}\text { Frequency } \\
\text { ('per week) }\end{array}$ & $\begin{array}{l}\text { Length } \\
\text { (weeks) }\end{array}$ & Supervision \\
\hline \multirow{4}{*}{$\begin{array}{l}\text { Nytrøen et } \\
\text { al. }{ }^{[8]}, 2019\end{array}$} & HIIT (AIT) & $\begin{array}{c}\text { Cardiopulmonary } \\
\text { test }\end{array}$ & $\begin{array}{c}\text { 81-93\% } \\
\text { peak effort }\end{array}$ & $\begin{array}{l}10 \text { min warm-up } \\
4 \text { bouts ( } 4 \text { min of } \\
\text { HIIT) and } 3 \text { bouts } \\
(3 \text { min of MICT) } \\
5 \text { min cooldown }\end{array}$ & 3 & $02 /$ mar & 39 & Nytrøen et al., \\
\hline & \multirow{3}{*}{ MICT (ACT) } & \multirow{3}{*}{$\begin{array}{c}\text { Cardiopulmonary } \\
\text { test }\end{array}$} & \multirow{3}{*}{$\begin{array}{c}60-80 \% \\
\text { peak effort }\end{array}$} & 10 min warm-up & \multirow{3}{*}{3} & \multirow{3}{*}{$02 /$ mar } & \multirow{3}{*}{39} & \\
\hline & & & & 25 min exercise & & & & \\
\hline & & & & 5 min cooldown & & & & \\
\hline \multirow{6}{*}{$\begin{array}{l}\text { Dall et al. }{ }^{[13]} \text {, } \\
2014\end{array}$} & \multirow{3}{*}{ HIIT (AIT) } & \multirow{3}{*}{$\begin{array}{c}\text { Cardiopulmonary } \\
\text { test }\end{array}$} & \multirow{3}{*}{$\begin{array}{c}>80 \% \\
\text { peakVO }\end{array}$} & 10 min warm-up & \multirow{3}{*}{3} & \multirow{3}{*}{3} & \multirow{3}{*}{12} & \multirow{6}{*}{$\begin{array}{l}\text { Dall et al., } \\
2014\end{array}$} \\
\hline & & & & 16 min exercise & & & & \\
\hline & & & & 10 min cooldown & & & & \\
\hline & \multirow{3}{*}{$\mathrm{MICT}(\mathrm{ACT})$} & \multirow{3}{*}{$\begin{array}{c}\text { Cardiopulmonary } \\
\text { test }\end{array}$} & \multirow{3}{*}{$\begin{array}{l}60-70 \% \\
\text { peakVO }\end{array}$} & 10 min warm-up & \multirow{3}{*}{3} & \multirow{3}{*}{3} & \multirow{3}{*}{12} & \\
\hline & & & & 45 min exercise & & & & \\
\hline & & & & 10 min cooldown & & & & \\
\hline \multirow{4}{*}{$\begin{array}{l}\text { Hermann et } \\
\text { al. }^{[19]}, 2011\end{array}$} & \multirow{3}{*}{ HIITa } & \multirow{3}{*}{$\begin{array}{c}\text { Cardiopulmonary } \\
\text { test }\end{array}$} & \multirow{3}{*}{$\begin{array}{c}80 \%, 85 \% \text {, and } \\
90 \% \text { of peakVO } 2\end{array}$} & 10 min warm-up & \multirow{3}{*}{3} & \multirow{3}{*}{3} & \multirow{3}{*}{8} & \multirow{4}{*}{$\begin{array}{c}\text { Hermann et } \\
\text { al., } 2011\end{array}$} \\
\hline & & & & 42 min exercise & & & & \\
\hline & & & & 10 min cooldown & & & & \\
\hline & $\begin{array}{c}\text { Control group } \\
\text { (sedentary?) } \\
\text { Only } \\
\text { education }\end{array}$ & $\begin{array}{c}\text { Cardiopulmonary } \\
\text { test }\end{array}$ & NR & NR & $N R$ & NR & NR & \\
\hline \multirow{4}{*}{$\begin{array}{l}\text { Nytrøen et } \\
\text { al. }{ }^{[18]}, 2012\end{array}$} & \multirow{3}{*}{ HIIT } & \multirow{3}{*}{$\begin{array}{c}\text { Cardiopulmonary } \\
\text { test }\end{array}$} & \multirow{3}{*}{$\begin{array}{l}85-95 \% \\
\text { HRmax }\end{array}$} & 10 min warm-up & & & & \\
\hline & & & & 16 min exercise & 3 & 3 & 8 & $\begin{array}{c}\text { Nytrøen et al., } \\
2012\end{array}$ \\
\hline & & & & NR cooldown & & & & \\
\hline & $\begin{array}{l}\text { Control group } \\
\text { (no } \\
\text { intervention) }\end{array}$ & $\begin{array}{c}\text { Cardiopulmonary } \\
\text { test }\end{array}$ & NR & NR & NR & NR & NR & \\
\hline & & & & 10 min warm-up & & & & \\
\hline & HIIT & Cardiopulmonary & $\begin{array}{l}60-80 \% \\
\text { peakVO }\end{array}$ & 16 min exercise & 3 & $\begin{array}{l}5 \% \text { week } \\
\text { (12 weeks) }\end{array}$ & 12 & \\
\hline Haykowsky et & & & & NR cooldown & & & & Nytrøen et al., \\
\hline & $\begin{array}{l}\text { Control group } \\
\text { (no } \\
\text { intervention) }\end{array}$ & $\begin{array}{c}\text { Cardiopulmonary } \\
\text { test }\end{array}$ & NR & NR & NR & NR & NR & \\
\hline
\end{tabular}

$\mathrm{ACT}=$ active recovery; $\mathrm{AIT}=$ aerobic interval training; $\mathrm{HIIT}=$ high-intensity interval training; $\mathrm{HR}=$ heart rate; $\mathrm{MICT}=$ moderate-intensity continuous training; NR=Not reported 


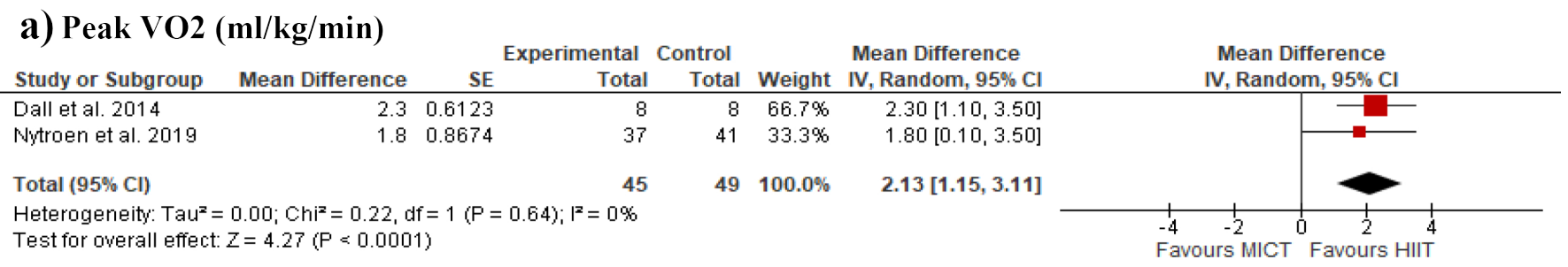

\section{b) Peak Hear rate (bpm)}

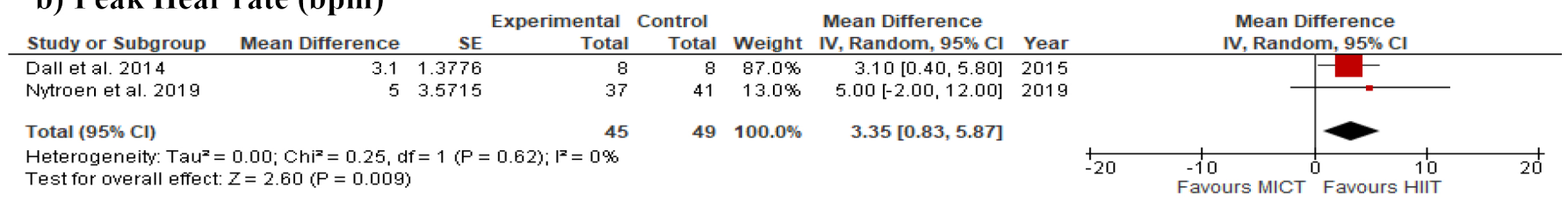

\section{c) Heart rate reserve (bpm)}

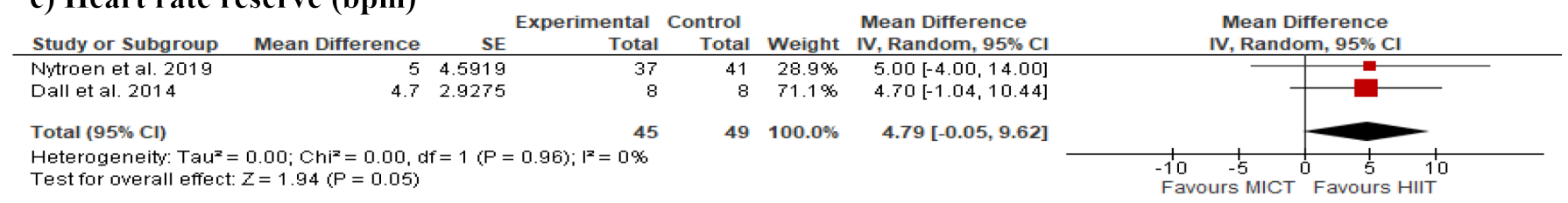

\section{d) Peak VO2 (ml/kg/min)}

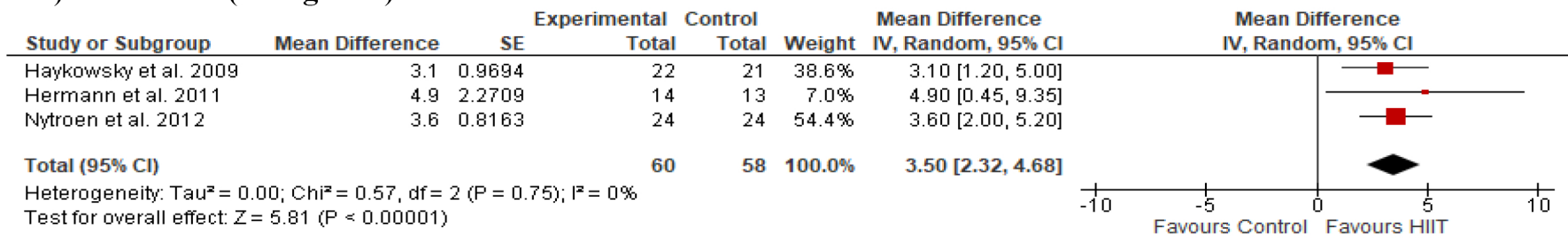

\section{e) Peak Heart rate (bpm)}

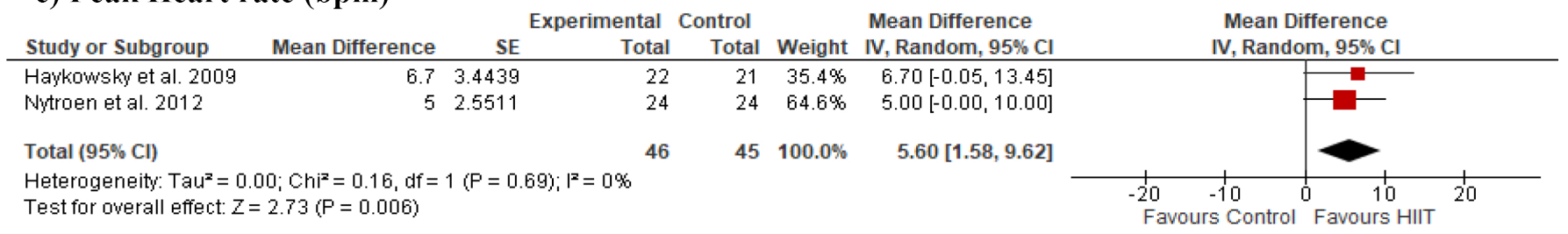

Fig. 4 - Forest plot showing meta-analyses of the high-intensity interval training (HIIT) vs. moderate-intensity continuous training (MICT) on a) peak oxygen consumption (peakVO2), b) peak heart rate, and c) heart rate reserve. Comparisons between HIIT vs. no exercise training on d) peakVO2 and e) peak heart rate were also shown. $\mathrm{Cl}=$ confidence interval; SE=standard error

(Figure 4B), and heart rate reserve $(\mathrm{MD}=4.8 ; 95 \% \mathrm{Cl}-0.05,9.6$; $P=0.05$ ) (Figure $4 \mathrm{C}$ ) compared to $\mathrm{MICT}$. Improvements on peakVO $2(\mathrm{MD}=3.5 ; 95 \% \mathrm{Cl} 2.3,4.7 ; P<0.00001)$ (Figure 4D) and peak heart rate $(\mathrm{MD}=5.6 ; 95 \% \mathrm{Cl} 1.6,9.6 ; P=0.006)$ (Figure 4E) were also found comparing HIIT and no exercise training. No data was available to compare heart rate reserve between HIIT and control without exercise. No between-study heterogeneity $\left(1^{2}=0 \%\right)$ was found in the meta-analyses.

\section{DISCUSSION}

Our systematic review found that HIIT was superior than MICT on peakVO 2 , peak heart rate, and heart rate reserve in $\mathrm{HTx}$ recipients. In recent years, a growing number of studies have suggested that HIIT is similar or even superior to MICT in peakVO, heart rate response, and quality of life improvements $[8,13,21]$.

A previous meta-analysis reported the efficiency of HIIT on peakVO $\mathrm{O}_{2}$ gains in $\mathrm{HTx}$ when compared to no exercise training ${ }^{[9]}$. However, our meta-analysis contributes to a better understanding of the effect size of HIIT when compared with the standard exercise intensity prescription (MICT). Additionally, some issues regarding the effects of exercise protocols must be addressed in relation to the apparent superiority of HIIT over MICT. In a recent review, Dun et al. ${ }^{[22]}$ argued that the exercise duration and ratio of high and low-intensity bouts are key factors that differentiate 
HIIT from MICT and may contribute to the patient's response. In general there are three main protocols of HIIT: long, medium, and short. The long-duration HIIT protocol (four minutes at high intensity - 85-95\% peakVO 2 - and three minutes at moderate intensity - $60-70 \%$ of peakVO $\mathrm{O}_{2}$ ) is the most widely used in patients with cardiovascular diseases. Another metaanalysis demonstrated that the long-duration HIIT protocols were associated with larger improvements in peakVO $\mathrm{O}_{2}$ in healthy individuals ${ }^{[23]}$. In our meta-analysis, the studies comparing HIIT to MICT used long-duration HIIT protocol. This may be one of the main factors behind the superiority of HIIT over MICT ${ }^{[22]}$

The concept of isocaloric protocol must also be considered when HIIT and MICT are compared. The superiority of HIIT over MICT disappeared when studies that used isocaloric protocols were analyzed in previous meta-analyses involving patients with coronary artery disease ${ }^{[11]}$ and heart failure ${ }^{[10]}$. In our analysis, only one study ${ }^{[23]}$ reported isocaloric protocol, which limits any pragmatic conclusion about HIIT superiority.

Additionally, our secondary analysis demonstrated that HIIT had superior effects to MICT in peak heart rate and heart rate reserve. In four of the five included studies, the mean time after transplantation was between four and six years ${ }^{[13,16-18]}$. Initially, we supposed that this superiority would be associated with cardiac reinnervation. Long-term HTx recipients are expected to show some degree of cardiac reinnervation, which nearly normalizes heart rate control. In contrast, newly $\mathrm{HTx}$ recipients display a denervated status and the heart rate response is markedly reduced compared to health individuals. On the other hand, in one study, HTx recipients were followed 8-12 weeks after $\mathrm{HTX}^{[12]}$. The apparent superiority of HIIT may be associated with the volume of training ${ }^{[23]}$. Additionally, the small number of studies and of isocaloric protocols does not allow us to fully support the superiority of HIIT over MICT in cardiac dynamics.

\section{Limitation}

Caution is warranted in interpreting the results of this study. One important limitation is the low number of studies comparing HIIT to MICT and the lack of isocaloric protocols. Another important limitation is that in just one study ${ }^{[13]}$ the patients were followed by a physical therapist in a 1:1 setting. This type of setting may guarantee that the patients reach the proper intensity prescribed. On the other hand, this type of setting may not be suitable in most cardiac rehabilitation centers around the world, especially in middle- and lower-income countries.

\section{CONCLUSION}

In conclusion, current available evidence suggests that HIIT is superior to MICT on peakVO 2 , peak heart rate, and heart rate reserve improvements in $\mathrm{HTx}$ recipients. However, new RCTs are necessary to analyze the influence of isocaloric protocols and different duration protocols on peakVO $\mathrm{O}_{2}$ in $\mathrm{HTx}$ recipients.

\section{No financial support. \\ No conflict of interest.}

\section{Authors' roles \& responsibilities}

LSRC Drafting the work; final approval of the version to be published; leading author

COG Substantial contributions to the acquisition of data for the work; final approval of the version to be published

RESF Substantial contributions to the acquisition of data for the work; final approval of the version to be published

PRSMF Statistical analysis and Substantial contributions to the conception or design of the work.

MGN Substantial contributions to the analysis of data for the work; revising the work; final approval of the version to be published

VRN Drafting the work and revising it; final approval of the version to be published

VOC Substantial contributions to the acquisition of data for the work; drafting the work; final approval of the version to be published

\section{REFERENCES}

1. Harris C, Cao C, Croce B, Munkholm-Larsen S. Heart transplantation. Ann Cardiothorac Surg. 2018;7(1):172. doi:10.21037/acs.2018.01.11.

2. Lavie CJ, Arena R, Earnest CP. High-intensity interval training in patients with cardiovascular diseases and heart transplantation. J Heart Lung Transplant. 2013;32(11):1056-8. doi:10.1016/j.healun.2013.08.001.

3. Yardley M, Havik OE, Grov I, Relbo A, Gullestad L, Nytrøen K. Peak oxygen uptake and self-reported physical health are strong predictors of longterm survival after heart transplantation. Clin Transplant. 2016;30(2):1619. doi:10.1111/ctr.12672.

4. Anderson L, Nguyen TT, Dall CH, Burgess L, Bridges C, Taylor RS. Exercisebased cardiac rehabilitation in heart transplant recipients. Cochrane Database Syst Rev. 2017;4(4):CD012264. doi:10.1002/14651858. CD012264.pub2.

5. Haykowsky M, Taylor D, Kim D, Tymchak W. Exercise training improves aerobic capacity and skeletal muscle function in heart transplant recipients. Am J Transplant. 2009;9(4):734-9. doi:10.1111/j.16006143.2008.02531.x.

6. Tomczak CR, Tymchak WJ, Haykowsky MJ. Effect of exercise training on pulmonary oxygen uptake kinetics in heart transplant recipients. Am J Cardiol. 2013;112(9):1489-92. doi:10.1016/j.amjcard.2013.06.037.

7. Kobashigawa JA, Leaf DA, Lee N, Gleeson MP, Liu H, Hamilton MA, et al. A controlled trial of exercise rehabilitation after heart transplantation. N Engl J Med. 1999;340(4):272-7. Erratum in: N Engl J Med 1999;340(12):976. doi:10.1056/NEJM199901283400404.

8. Nytrøen K, Rolid K, Andreassen AK, Yardley M, Gude E, Dahle DO, et al. Effect of high-intensity interval training in De Novo heart transplant recipients in Scandinavia. Circulation. 2019;139(19):2198211. Erratum in: Circulation. 2019;140(17):e737. doi:10.1161/ CIRCULATIONAHA.118.036747.

9. Perrier-Melo RJ, Figueira FAMDS, Guimarães GV, Costa MDC. Highintensity interval training in heart transplant recipients: a systematic review with meta-analysis. Arq Bras Cardiol. 2018;110(2):188-94. doi:10.5935/abc.20180017.

10. Gomes Neto M, Durães AR, Conceição LSR, Saquetto MB, Ellingsen $\varnothing$, Carvalho VO. High intensity interval training versus moderate 
intensity continuous training on exercise capacity and quality of life in patients with heart failure with reduced ejection fraction: a systematic review and meta-analysis. Int J Cardiol. 2018;261:134-41. doi:10.1016/j. ijcard.2018.02.076.

11. Gomes-Neto M, Durães AR, Reis HFCD, Neves VR, Martinez BP, Carvalho VO. High-intensity interval training versus moderate-intensity continuous training on exercise capacity and quality of life in patients with coronary artery disease: a systematic review and meta-analysis. Eur J Prev Cardiol. 2017;24(16):1696-707. doi:10.1177/2047487317728370.

12. Dall CH, Snoer M, Christensen S, Monk-Hansen T, Frederiksen M, Gustafsson F, et al. Effect of high-intensity training versus moderate training on peak oxygen uptake and chronotropic response in heart transplant recipients: a randomized crossover trial. Am J Transplant. 2014;14(10):2391-9. doi:10.1111/ajt.12873.

13. Moher D, Liberati A, Tetzlaff J, Altman DG; PRISMA Group. Preferred reporting items for systematic reviews and meta-analyses: the PRISMA statement. Ann Intern Med. 2009;151 (4):264-9, W64. doi:10.7326/00034819-151-4-200908180-00135.

14. Higgins JP, Green S, editors. Cochrane handbook for systematic reviews of interventions [Internet]. Version 4.2.6. Chichester (UK): John Wiley \& Sons, Ltd.; 2006 [updated 2006 Sep; cited 2006 Nov 3]. 257 p. Available from: http://www.cochrane.org/resources/handbook/handbook.pdf

15. Higgins JP, Altman DG, Gøtzsche PC, Jüni P, Moher D, Oxman AD, et al. The Cochrane collaboration's tool for assessing risk of bias in randomised trials. BMJ. 2011;343:d5928. doi:10.1136/bmj.d5928.

16. Cochran WG. The Combination of Estimates from Different Experiments. Biometrics. 1954;10(1):101-29. doi:10.2307/3001666.

17. Higgins JP, Thompson SG, Deeks JJ, Altman DG. Measuring inconsistency in meta-analyses. BMJ. 2003;327(7414):557-60. doi:10.1136/ bmj.327.7414.557.

18. Nytrøen K, Rustad LA, Aukrust P, Ueland T, Hallén J, Holm I, et al. Highintensity interval training improves peak oxygen uptake and muscular exercise capacity in heart transplant recipients. Am J Transplant. 2012;12(11):3134-42. doi:10.1111/j.1600-6143.2012.04221.x.

19. Hermann TS, Dall CH, Christensen SB, Goetze JP, Prescott E, Gustafsson F, Effect of high intensity exercise on peak oxygen uptake and endothelial function in long-term heart transplant recipients. Am J Transplant. 2011;11(3):536-41. doi:10.1111/j.1600-6143.2010.03403.x.

20. Yardley M, Gullestad L, Bendz B, Bjørkelund E, Rolid K, Arora S, et al. Long-term effects of high-intensity interval training in heart transplant recipients: a 5-year follow-up study of a randomized controlled trial. Clin Transplant. 2017;31(1). doi:10.1111/ctr.12868.

21. Dun Y, Smith JR, Liu S, Olson TP. High-intensity interval training in cardiac rehabilitation. Clin Geriatr Med. 2019;35(4):469-87. doi:10.1016/j. cger.2019.07.011.

22. Bacon AP, Carter RE, Ogle EA, Joyner MJ. VO2max trainability and high intensity interval training in humans: a meta-analysis. PLoS One. 2013;8(9):e73182. doi:10.1371/journal.pone.0073182.

\section{Supplementary Content \\ Search Strategy:}

\section{PubMed:}

("heart recipient" OR "heart transplant recipient" OR "heart transplant" OR "cardiac transplant" OR "heart graft" OR "heart transplantation"[Mesh] OR "cardiac transplantation") AND ("exercise training" OR "interval training" OR "high intensity interval training" OR "high intensity training" OR "intermittent training") OR "sprint training") AND (randomized controlled trial[Publication Type] OR (randomized[Title/Abstract] AND controlled[Title/Abstract] AND trial[Title/Abstract])

\section{Scopus:}

("Heart Transplantation" OR "Heart Grafting" OR "Cardiac Transplantation" OR "cardiac transplantations") AND ("High Intensity Interval Training" OR "Sprint Interval Training" OR "Sprint Interval Trainings" OR "High-Intensity Intermittent Exercise")

\section{Cochrane Library:}

("Heart Transplantation" [Mesh term]) AND ("High-Intensity Interval Training"[Mesh term]) 